\title{
ADVERTISING IN SMALL AND MEDIUM ENTERPRISES - THE PRACTICAL EXAMPLES AND ADVICES
}

\author{
Janusz, K. Grabaral \\ Bartlomiej Okwiet ${ }^{2}$
}

\begin{abstract}
Advertising lever trade "- it is not possible to determine the author of these "winged words", but we know that this slogan reviewers whole truth about the role of advertising performance throughout the economy and how its effective use may contribute to the development of every enterprise operating in the national, regional or local market. Nowadays, there is an enterprise that never would apply this tool to promote their services or products. Any, even the single company wanting to enter to the market and growing is forced to use the tool which is advertising. The following article presents the essence of advertising, its characteristics and shows four different companies that use its various forms to promote their products and services.
\end{abstract}

Keywords: advertising, enterprise, marketing mix, Internet

JEL: $M 19$

\section{Advertising characteristics}

The most common definition of advertising saying that "advertising is impersonal, payable and addressed to the mass-market form of communication (Jefkins F,2000)." According to the Institute of Practitioners in Advertising, advertising is an information affecting the future consumers (inducing them to buy) and presenting a product or service in perspective, noting that these products or services are offered at the lowest possible prices (The Institute of Practitioners in Advertising,)

Characteristics of advertising are as follows (Wright R, 2000):

- This information is directed to the target group of people,

- It is used by organizations, both profitable and non-profit organizations, they may be government and private,

- Most of the advertising is paid and is broadcast via television, radio, posters, billboards or channels displaying only ads that are in possession of the organization who are not advertisers,

- Despite the fact that everything might be advertised, the vast majority of today's advertising focuses on the advertising of products or services,

- Most of the advertising are used to promote companies and brands of products,

- Advertising is a kind of mix consisting of advertising campaigns, PR, public and personal selling process.

The most common classification is the division of advertising "above the line" and "below the line". "Above the Line" is an advertisement in a major media (television, newspapers, radio) and responsible for creating a suitable advertising campaign is an advertising agency that is paid on this account. The range of this type of advertising is usually wide. "Below the line" is advertising in all other forms - the so-called. direct mail, banners, bags, posters. It can also take the form of sponsorship and also uses the Internet to reach out to as many people. Using all media except the tools that have been classified into "above the line". There is also a classification of "through the

\footnotetext{
${ }^{1}$ Janusz K. Grabara prof. at Czestochowa University of Technology,e-mail: janusz@grabara.eu

2 Bartlomiej Okwiet, PhD. student, Faculty of Management, Czestochowa University of Technology, e-mail: bartomoliej_O@yahoo.com
} 
line", which is a peculiar combination of these two, an example might be here an advertising campaign that is broadcast on television but also takes the form of promotion. (Tibbs A.,2010),

The purpose of advertising is to fill the communication needs which have every company, product, brand or service. Advertising is the tool used most often to increase sales, provide information and sometimes even education, going forward, advertising can be a tool used to (McRury I ,2009):

- Create awareness about the actions of industry, corporate or brand,

- Inform, educate, and implement,

- Strengthening, reminders, changes in attitudes and opinions,

- Creation the favorite images,

- manipulate and persuade,

- Introduction products or services' samples,

- Strengthening and re-buying the product,

- Promotion of other forms of advertising campaign

- motivate the questioning,

- Provide sales guidance for the Sales Department,

- Support sales of products and services.

Advertising refers to the rational and emotional attributes as well as the instinct of human nature.

In the universal concept of marketing mix (product, price, distribution, advertising), advertising acts as an independent element, in the process of its creation involved a lot of elements that can determine its effectiveness and impact on increasing sales of the product or service (Sutherland M., 2008):

- The size, strength and time impact of advertising is dependent on product's life cycle at which the advertised product or service is. The impact of advertising is much greater at the time of placing on the market than at the time of withdrawal,

- Marketing research provides information on the motivations, preferences and attitudes of potential clients that affect the choice and not just the general concept of advertising but also in the choice of the form in which it will be transmitted,

- Name and brand of product most often are created by the advertising division of the company, both of these elements play a large role throughout the whole campaign,

- advertising and PR department also takes an active part in promoting and advertising the appearance of the product,

- The marketing department is also choosing the right style for a particular campaign,

- Price plays a very important role in advertising - it determines the level of whether a product is a good or so-called luxury. opportunity. Price can be a very competitive argument as the recipient of the ads are in the majority of customers informed and pay close attention to the prices,

- Same products may exist in one campaign as such complementary products or any type of product may require a separate advertising campaign

- Packaging also plays a large role in advertising, on how it is perceived by prospective buyers may depend on the volume of sales of the product. Packaging should be a specific characteristic mark of the product so that it will be quickly found on the shelves. Currently, it became very popular to use packages that are environmentally friendly - recycled undergo or undergo rapid degradation. Using this type of packaging, the company sends a signal that it is having regard to company environmental issues and contribute to its preservation,

- The distribution process involves the transmission of various forms of advertising content, such as television, newspapers, radio, Internet,

- The sales department should be familiar with all elements of an advertising campaign which also is a tool to support their main activities in trade, 
- Education Marketing focuses on creating the appropriate market situation whereby the advertising shall have an effect

- Many corporations and government agencies for advertising purposes, often using the socalled. trade press, using their image up a kind of institutional advertising,

- Before you start your ad campaign, the investigator should test its potential effectiveness,

- The use of sales promotion can sometimes replace the traditional way of selling as well as the traditional way of advertising,

- After an advertising campaign advertising department often performs calls to potential customers in order to remind that the product is still available in the market and After-sales

- Through advertising of complementary products or accessories, the company can gain the trust and loyalty of customers,

- Addressing the buyers during the breaks between the advertising campaigns greatly helps to remember the brand or product.

An created advertising campaign should be based on five main points (Kubicka H.,Taranek O, 2009):

- What is the main purpose of the sale?

- Time to reach for - a week, month, year?

- How is the strategy - whether it is intended to attract new customers and increase sales at the old customers?

- What tactics are most appropriate for the proposed ad, which tools should be used and what form is to take the ad?

- What will be the cost of the entire campaign and whether it is a good investment?

As seen the above, the creation of ads and entire advertising campaign is a long and complicated process in which people are involved with both the advertising department or advertising agency company, but also people who, apparently, have nothing to do with party advertising companies. To campaign to succeed, its creators have put a lot of questions and develop the most optimal solution.

\section{Advertising types and forms}

Initially, the ad appeared mostly in paper form, as an ad in the newspaper or advertising on the product packaging. But with the development of technology and the advent of radio and television, also created new forms of advertising. Currently, it stands out a lot of the most popular forms are presented below.

Television advertising is probably the most popular form due to the fact that almost every household has a television set. This is not advertising for small businesses, because due to its high cost, only few companies are interested in this form. Television advertising remains the domain of large companies and corporations who, through television advertising have the ability to reach the largest audience that spans the entire country.

In addition to television advertising, popular and widely used form of advertising is Internet advertising. Despite the fact that almost every household has a computer, however, only $36 \%$ of households declares as access to the Internet (www.interstats.pl). However, the Internet is a medium which is characterized by a constant increase in reach and it can be assumed that in the near future will become as common as a television presence. Online advertising is an effective advertising tool for both small and large enterprises. The Internet offers many ways to the existence and advertise products or services offered by the enterprise (Jacobs H,2006):

- banner - this is the most popular form of online advertising, it usually appears at the top of the website,

- button - it is a form of advertising in the shape of a small, rectangular graphic element,

- interstital - a form of advertising is taking the shape of the full-screen animation, 
- pop up - this is the window that opens on the active side of the browser, it should be noted here that it is very annoying form of advertising, and most people respond to that ad irritation and it closes automatically without going into the content of what a pop-up forward, now hardly used,

- pop - unders - unlike pop-up window that opens into the active side of the browser and becomes visible only when it is closed,

- brandmark - a window opening above the active site but does not cover it because the site is completely transparent, by creating a different shapes and colors are becoming an attractive form of online advertising,

- toplayer - this is a lasting max. 10 seconds animation that takes place on the active browser window,

- expand - it is a developed form of banner, originally developed in the full version, covering the active site and then, after a few seconds, folds to the size of the banner,

- scroll -this the form of advertising that follows the user scrolls the active site,

- watermark - is to put the company logo in the background site, it takes the form of wallpaper,

- advertorial - this is the article purchased by the company, describing the advantages of such a product,

- comet cursor - the image field which is linked to the mouse and follows him,

- sponsorship - in the form of advertising there is a strong integration with a particular advertiser's site, which usually takes the shape of a resemblance to the advertised product,

- mailing - they are advertised a list sent to Internet users via email,

- advertising in the newsletter - contained in the bulletin, which, unlike the traditional newsletter is sent to users by e-mail

- scroller - it's an advertising bar displayed at the bottom of the site and not changing its position.

Besides, the above-mentioned forms, there are many other forms of advertising that can be used by the company (Walker Laid P., 2001) :

- radio advertising,

- press advertisement,

- cell phones

- traditional mail,

- cinema

- buzz marketing,

- large advertising surface,

- gadgets,

- flyers, brochures, posters,

- alternative advertising.

Taking into account the strategic objectives of the company it intends to achieve by means of advertising, including ads, you can distinguish the following types (Lee M., Johnson C.,2005):

- advertising for information, draws attention to buyers on the benefits they can achieve by purchasing the advertised product or service

- that an ad like the product / service is still available in the market,

- advertising whose purpose is to promote and present point of view of the company in case of controversial issues, such as on environmental protection,

- curtain advertising, which is to take attention of buyers from one product to another, newly introduced to the market, the product of the same brand,

- targeted advertising that directs customers to the outlets where they can purchase the product / service,

- professional advertising is usually addressed to the people of the liberal professions, such as doctors, musicians, visual artists, 
- presented in comparative advertising are the advantages and features of the product in comparison with those of other brand products,

- advertising accentuates the distinctive competitive advantages compared to products of its competitors,

- advertising associated with the PR (Public Relations), whose main purpose is to provide information about the activities undertaken by the company,

- aggressive advertising, by invoking a strong impression, induces buyers to act quickly, such as immediate purchase the product or service,

- stresses the prestigious advertising much of the product / service, highlights their uniqueness and special purpose, it creates the impression of exclusivity and inaccessibility,

- defensive in advertising, the product / service are presented in opposition to the advertising competition.

With such a wide selection of both forms and types of advertising, every enterprise, whether offering products or services, can find a form of advertising which is appropriate for itself and for its practical use, enter the market, increase sales and earn a good reputation among customers. Below are four companies differ in the nature of the activity, and therefore, using different forms and types of advertising in order to achieve those objectives.

\section{Advertising in the SME's (small and medium enterprises) sector}

The enterprises presented below differ from each profile of activity, but all operate in the SME sector. The first is a printing company that provides comprehensive support for clients ranging from graphic design, printing and after the final installation of a poster or banner. Printing contract takes all kinds, from leaflets after spending several thousand books. Its clients are individuals and whole companies. In this way, printing is a company operating in the $\mathrm{B} 2 \mathrm{~B}$ and $\mathrm{B} 2 \mathrm{C}$ area. $\mathrm{B} 2 \mathrm{~B}$ area (Business to business) means that a customer of a company is another business unit, company, municipality or government. B2C area (Business to Client) indicates that enterprises' customers are the private individuals. Another company is a manufacturer of trolleys. It stands out compared to other manufacturers of trucks from Czestochowa (must add that the City is a kind of Mecca for trolleys manufacturers) as the only manufacturer who is recognized abroad. Trolleys produced by it go to stores across the country and have seen on the streets of Slovakia, the Czech Republic, Hungary, Lithuania and Russia for a few years. The company manufactures trolleys in addition to a wide range of products for kids - car seats, high chair, pushchairs or beds. A few years ago, it has created another Premium product line. Since its finished product are purchased by the private individuals, the company operates in the $\mathrm{B} 2 \mathrm{C}$ area. Another company working in the horticultural industry, involved in green spaces belong to the city. Its offer is directed only to business partners and thus is a B2B company. Currently supports over $70 \%$ of urban green areas of the city, and every year its order book increased by orders from the following municipalities, located near the Czestochowa city. The last company is a company producing car carpets. There are in the market for over 30 years and from 15 specialized in manufacturing car carpets, which has more than 900 on offer. Its main customer is the Fiat group, but the company also runs sales individual, carrying out orders from private individuals. Guided by its offer, both to business partners and individuals, the company operates in the area, both B2B and B2C.

Despite the fact that all the above presented companies operate in different industries and significantly differ from each profile of activity. This, however, each of these companies use the tool which is advertising. This diversity action profile, results for each company used different forms of advertising will bring a satisfactory result.

It should be noted that only two of these companies have websites, on these pages can be found basic information about the enterprise, review the range of products, a company engaged in producing car carpets put on its website an opportunity to purchase with the home- delivery. Manufacturer's website serves as a representative trucks, it contains a directory of all the products, 
information on service and warranties as well as a list of points where you can buy its products. The other two companies did not have a website, and bearing in mind that more and more it has access to the Internet and many people will be significantly easier to become familiar with the offer of the company without having to leave home, both companies should think about creating such a page (as one of the forms of advertising). In the case of printing on the page, in addition to basic information, you may find a full range of the company along with pricing and the ability to send the finished design to printing and print the final receipt by mail or courier. This solution should cause the printer customers who want to use the printing services from time to time by outsourcing to print, such as paper or thesis. The company engaged in the green areas on your website can include information about the history of their business (this is a family business for over 30 years of existence on the market). The site could find galleries of land remaining under the care of the company together with the tender for the following municipalities or counties.

Whereas other forms of advertising, each of the above companies to easily find an appropriate form of advertising for themselves. For all the good form of advertising companies will be called. buzz marketing, advertising is transmitted through direct verbal communication. Such a buzz marketing is more reliable when taking part in it so. individuals, it is common knowledge that one person is more inclined to believe the opinion of the spoken by a person other than the traditional means of information supplied advertising.

For companies dealing with production trucks and car carpets, good form of advertising can be product placement (product placement in the middle of the media) in a television program having a similar theme to their profile. Manufacturer of trucks can occur in breakfast television which are frequently discussed topics related to children and recipients of such programs are often young mothers. Manufacturer of floor mats can get product placement in the car in which they presented the advantages of each product. A good program for the manufacturer of rugs can be "controlled purchase" broadcast by TVN, is a program that has a fairly large audience, and product placement in this type of program is a very good idea.

Another form of advertising can become a forum established by the company, in the case of a company engaged in green spaces can be a forum for urban greenery, gardens and caring. The company may post photos online showing the results of their activities and answer the question. The lift manufacturer can create a specialized forum in which to advise how the truck is the most suitable, what to look for when buying and what accessories might be necessary. Will also allow individual selection of tastes trolley mothers, fathers a child with simultaneous convenience, but which will be transported in the trucks.

Printing can also advertise through the creation of skins for different kinds of events festivals, fairs, or playgrounds. The manufacturer of rugs can advertise through participation in car shows.

\section{Conclusions}

It is obvious that every enterprise having a different profile of activity is able to find a form of advertising that is most suitable for it and thus, significantly contribute to growth or increase the number of contract customers. As the advertising market is constantly changing, every moment, there are new advertising strategies and new forms of it, every company has the opportunity to benefit from the diversity that represents a tool advertising. 


\section{References}

1. Jacobs H., 2006. Advertising, Career FAQ's, NY

2. Jefkins F., 2000. Advertising, Pearson Education Limited, Essex

3. Kubicka H., Taranek O., 2009. Kody kultury. Interakcja, transformacja, synergia, Towarzystwo Przyjaciół Polonistyki Wrocławskiej, Wrocław

4. Lee M., Johnson C., 2005. Principles of Advertising, The Haworth Press, NY

5. McRury I., 2009. Advertising, Routledge, NY

6. Sutherland M., 2008. Advertising and the mind of the consumer, Allen\&Unwin, Crows Nest

7. Tibbs A., 2010. Advertising, Trevor Beattle, NY

8. Walker Laid P., 2001. Advertising Progress, The John Hopkins University Press, NY

9. Wright R., 2000, Advertising, Pearson Education Limited, Essex

10. www.interstats.pl

11. www.ipa.co.uk - site of The Institute of Practitioners in Advertising 